\title{
COVID-19 and the reenactment of mass masking in South Korea
}

\author{
Heewon $\mathrm{Kim}^{1} \cdot \mathrm{Hyungsub}^{\mathrm{Choi}}{ }^{2}$ (D)
}

Received: 31 December 2020 / Accepted: 12 March 2021 / Published online: 25 March 2021

(C) Springer Nature Switzerland AG 2021

\begin{abstract}
How can we explain the divergence of social commitment to mass masking as public health measures in the global response to COVID-19? Rather than searching for deep-rooted cultural norms, this essay views the contemporary practice as a reenactment of multiple layers of accumulated socio-material conditions. This perspective will allow us to pursue a comparative study of the social history of mask-wearing around the world.
\end{abstract}

Keywords COVID-19 $\cdot$ Mass masking $\cdot$ South Korea

The Coronavirus Disease-19 (COVID-19) pandemic sparked some debate on the uneven public acceptance of facial masks around the world. One American observer pointed to the cultural practice of "stigmatizing mask-wearing" in an attempt to account for the divergent behavior (Friedman, 2020). Social media was replete with images during the Spanish flu pandemic a century ago showing Americans and Europeans wearing masks to protect themselves. Some of these postings derived from the work of a medical anthropologist, who have studied the origins of facial masks as protective devices during the 1910-11 Manchurian plague (Lynteris, 2018). As historian Andrew Gordon commented in a recent blog post, there was a "deepened commitment to masks... in East Asia and the disappearance of the

Hyungsub Choi

hchoi@seoultech.ac.kr

Heewon Kim

heewonkim@kaist.ac.kr

1 Graduate School of Science, Technology, and Policy, KAIST, 291 Daehak-ro, Yuseong-gu, Daejeon 34141, Republic of Korea

2 School of Liberal Arts, Seoul National University of Science and Technology, 232

Gongneung-ro, Nowon-gu, Seoul 01811, Republic of Korea 
commitment in at least one Western nation [the United States]" in the two decades before and after World War II (Gordon, 2020).

Rather than turning to deep-rooted cultural factors, we wish to pay attention to more recent precedents that explain the widespread acceptance of "mass masking" in South Korea. ${ }^{1}$ Here, as in other East Asian contexts, the use of masks has been introduced, largely through Japan, as instruments of public health responses against the spread of infectious diseases since at least the early twentieth century (Hyun \& Sumida, 2020). Although masking remained as one of the standard measures later in the century, it was by no means a stable fixture. We argue that the current practice of mass masking in South Korea was a result of reenacting the experience with facial masks. In other words, what we see in South Korea today is neither a product of ingrained cultural values, nor a direct continuation of the century-old habit of mask-wearing. A more direct precedent could be found in the heightened awareness toward airborne pollutants in the early twenty-first century.

In the mid-2000s, the South Korean public grew increasingly concerned with "yellow sand" or hwangsa and Particulate Matter (PM). The perceived environmental crisis opened up a new market for disposable facial masks labeled as "hwangsa masks." Excessive competition led to deteriorating quality, which forced the government to intervene. In 2008, the Korea Food and Drug Administration (KFDA) issued a quality guideline, setting the standard for a new category of "healthcare masks." Now manufacturers were required to go through a strict test to assure the quality standard of facial masks. Only those products that passed the test were allowed to attach the Korea Filter (KF) 99, 94, and 80 label, depending on the filtration efficiency (Shin, 2008). With the new certification system in place as a technical platform, domestic production of facial masks gradually increased, making highquality disposable masks an everyday artifact easily found in local drugstores and supermarkets.

The widespread availability and familiarity with facial masks served as a baseline for public behavior in the COVID-19 pandemic. When the pandemic hit in late January 2020, the South Koreans were already conditioned to flock to drugstores to purchase KF-certified masks. This inevitably led to a temporary shortage of masks. It is important to note that the "mask crisis" occurred even as experts in the Korea Center for Disease Control and Prevention (KCDC) were uncertain of the efficacy of mass masking. Although the KCDC recommended KF-certified masks only for front-line medical workers (following the World Health Organization guidelines at the time), the South Korean public continued to stockpile disposable masks, exacerbating the mask crisis. In response, the government instituted an equitable mask distribution scheme, mobilizing $80 \%$ of the domestic mask production at a set price. Beginning in early March, South Koreans were

\footnotetext{
1 This note belongs to the Topical Collection "Seeing Clearly Through COVID-19: Current and future questions for the history and philosophy of the life sciences", edited by G. Boniolo and L. Onaga.

We define "mass masking" as a regime recommending (or sometime mandating) the use of facial masks for the general public, even for those without noticeable symptoms associated with the infectious disease.
} 
allowed to purchase 3-5 healthcare masks per week at a regulated price of 1,500 won (approximately USD 1.30) per mask (Kim, 2020).

This is not to say that the South Korean mass masking practice during COVID19 was a direct continuation of that in response to airborne pollutants during the previous decade. Masks for hwangsa and PM were intended to protect oneself from toxic pollutants; masks for COVID-19 were to protect both oneself and the community from the infectious disease. Nevertheless, the environmental crisis of the mid-2000s helped build the material basis for the timely and sufficient production of high-quality masks. It was upon this basis that the South Korean public could reenact mask masking in response to COVID-19 in 2020. Therefore, the widespread acceptance of facial masks in South Korea should not be seen as a product of some abstract cultural norm, but as a reactivation of available sociomaterial resources to an entirely different set of challenges.

Seen in this light, it is possible to compare the historical and socio-material conditions within East Asia, as they reenacted mass masking utilizing disparate precedents. For example, the Severe Acute Respiratory Syndrome (SARS) epidemic of 2003 served as an important template for Taiwan and People's Republic of China (Sin, 2016; Wu, 2020). In Japan, the prevalence of hay fever, or kafunsho, in the 1980s and 1990s was one of the critical junctures for the widespread acceptance of mask-wearing (Horii, 2014). Each of these diverse experiences shaped the responses to the COVID-19 pandemic in the respective East Asian countries. A closer comparative analysis will lead to a richer understanding of the social history of mass masking around the world.

Acknowledgements An earlier version of this article has been presented at the workshop on "SocioMaterial History of Masked Societies in East Asia," organized by the Max Planck Institute for the History of Science. We thank the workshop organizers (Jaehwan Hyun, Noa Hegesh, and Lisa Onaga) and the two reviewers of this journal for helpful comments.

\section{References}

Friedman, U. (2020). Face masks are in. The Atlantic. April 3, 2000. Available at https://www.theat lantic.com/politics/archive/2020/04/america-asia-face-mask-coronavirus/609283/

Gordon, A. (2020). Historical context for COVID 19 policies in Japan and Asia (1). Tokyo College Blog. June 5, 2020. Available at https://www.tc.u-tokyo.ac.jp/en/weblog/1896/

Horii, M. (2014). Why do the Japanese wear masks? A short historical review. Electronic Journal of Contemporary Japanese Studies, 14(2). July 29, 2014. Available at http://www.japanesestudies. org.uk/ejcjs/vol14/iss2/horii.html/

Hyun, J., \& Sumida T. (2020). The material lives of masks in Japan and South Korea. The MaskArrayed. October 2, 2020. Available at https://themaskarrayed.net/2020/10/02/the-materiallives-of-masks-in-japan-and-south-korea-a-conversation-between-jaehwan-hyun-and-tomoh isa-sumida/

Kim, E. T. (2020). How South Korea solved its face mask shortage. New York Times. April 1, 2020.

Lynteris, C. (2018). Plague masks: The visual emergence of anti-epidemic personal protection equipment. Medical Anthropology, 37(6), 442-457.

Shin, C. (2008). Performance standards of yellow sand masks. Report for Service Research and Development, 070282-hwajangpum-26. 
Sin, M. S. Y. (2016). Masking fears: SARS and the politics of public health in China. Critical Public Health, 26(1), 88-98.

Wu, C. (2020). The making of mass medical masking during SARS in Taiwan. Paper presented at the Socio-Material History of Masked Societies in East Asia workshop, Max Planck Institute for the History of Science. 26 October 2020.

Publisher's Note Springer Nature remains neutral with regard to jurisdictional claims in published maps and institutional affiliations. 